\title{
Toll-like Receptor 7 Agonist DSP-0509
}

National Cancer Institute

\section{Source}

National Cancer Institute. Toll-like Receptor 7 Agonist DSP-0509. NCI Thesaurus. Code C153314.

A synthetic, small molecule, toll-like receptor (TLR) 7 agonist, with potential immunostimulatory and antineoplastic activities. Upon intravenous administration, TLR7 agonist DSP-0509 activates TLR7, resulting in type I interferon secretion and activation of cytotoxic T-lymphocyte (CTL)-mediated anti-tumor immune responses. TLR7 is a member of the TLR family, which plays a fundamental role in pathogen recognition and activation of innate immunity. 